Vol. 3, N².1., p. 189-214, junio, 2019

\title{
Procedimientos contables y tributarios en las importaciones de la empresa Tracto Oruga y su afectación en el costeo y utilidades.
}

\section{Accounting and Tax Treatment for imports in the Company Traco Oruga and Affectation of Costs and Profits}

Paulina Elizabeth Iñiguez Orellana. ${ }^{1}$, Cecilia Ivonne Narváez Zurita. ${ }^{2}$ \& Juan Carlos Erazo Álvarez. ${ }^{3}$

DOI: https://doi.org/10.33262/visionariodigital.v3i2.1.552

\begin{abstract}
.
This research aims to identify the current problems of the company Tracto Oruga located in the canton Loja, based on the review of the financial statements during the period 2018 according to the regulatory compliance of accounting, tax, and customs. With this as its foundation, the study wants to solve business issues regarding the cost of importing and the company's profits, which are by the theoretical foundations of Accounting.

Accordingly, the procedures have been developed under a conceptual structure which has incorporated tax and customs variables in the accounting treatment and the assessment of the company performance. For details on planned activities, flow charts have been designed, as well as procedures and departmental roles and responsibilities, besides the objectives to achieve. Finally, the proposal submits a journal entry in

${ }^{1}$ Universidad Católica de Cuenca, Posgradista Maestría en Contabilidad y Auditoría, Cuenca, Ecuador, peiniiguezo096@psg.ucacue.edu.ec

${ }^{2}$ Universidad Católica de Cuenca, Subdirección de Posgrado, Cuenca, Ecuador, inarvaez@ucacue.edu.ec

${ }^{3}$ Universidad Católica de Cuenca, Subdirección de Posgrado, Cuenca, Ecuador, jcerazo@ ucacue.edu.ec
\end{abstract}


accounting for the written record of import transaction from purchase to the final sale of their products

Keywords: Accounting Process, Accounting Standards, Inventory, Financial Statements.

\section{Resumen.}

La presente investigación busca identificar la problemática actual de la empresa Tracto Oruga de la ciudad de Loja, a partir de la revisión de los estados financieros del año 2018, en temas vinculados al cumplimiento de la normativa contable, tributaria y aduanera. En este sentido, se pretende demostrar que mediante la implementación de procedimientos estructurados bajo las normativas vigentes y en el marco de los fundamentos teóricos de la ciencia contable se puede dar solución a problemas empresariales relacionados con el costeo de importación y las utilidades de la empresa.

En consecuencia, los procedimientos se desarrollaron bajo una estructura conceptual que incorporó las variables tributarias y aduaneras en el tratamiento contable y en la evaluación del desempeño de la empresa. Se diseñaron flujogramas que refieren al detalle las actividades a desarrollar, se describieron los procedimientos y funciones por departamento, así como los objetivos que se pretenden alcanzar, finalmente en la propuesta se presentaron formatos de asientos contables que deberán ser utilizados durante las operaciones de importación desde la compra hasta la comercialización o venta final de sus productos.

Palabras clave: procedimientos contables, normas contables, inventarios, estados financieros

\section{Introducción.}

Siendo el proceso contable, una herramienta para conocer la situación económica-financiera de una empresa, éste se debe realizar de acuerdo a conocimientos, normas y principios contables, encaminados a obtener información fidedigna y de fácil comprensión para los administradores y dueños de las empresas. En el mismo sentido, al momento de ejecutar un proceso de importación, es preciso conocer los requisitos y procedimientos que se deben ejecutar, mismos que tendrán repercusión de forma directa en la información contabletributaria; esto con el fin de evitar errores en su presentación para el cumplimiento de las 
disposiciones establecidas por el Servicio de Rentas Internas (SRI) y Servicio Nacional de Aduana del Ecuador (SENAE).

Desde esta perspectiva, Omeñaca (2017) manifiesta que el objetivo de la contabilidad es informar el aspecto económico-cuantitativo como económico-financiero de una entidad, utilizando reportes de inventarios y balances, así como a través de estados financieros, para conocer el resultado, sea éste ganancia o pérdida, obtenido en un determinado periodo. La información contable tiene como finalidad reflejar la situación económica y financiera de la empresa, a través de un proceso que contempla pasos secuenciales correspondientes a las transacciones, desde su inicio hasta concluir con la presentación ordenada de la información en los estados financieros, facilitando la toma de decisiones.

De acuerdo a la Norma Internacional de Contabilidad NIC 1, la finalidad de los estados financieros es cubrir las necesidades de información que tienen los diferentes usuarios; en éstos se debe indicar el nombre de la entidad, mencionar si corresponden a una empresa individual o sucursales, periodo de tiempo y moneda del país. Carvalho (2009) menciona los siguientes estados financieros: (a) balance general, (b) estado de resultados, (c) estado de cambios en el patrimonio, (d) estado de flujos de efectivo y, también incluye las políticas contables y notas explicativas.

El balance general, es un estado básico de información empresarial, cuya finalidad es mostrar el posicionamiento financiero de un ente económico; consta de un encabezamiento que contiene: denominación de la entidad, denominación del estado financiero y fecha; el cuerpo constituido por: activos, pasivos y patrimonio, mostrando de una forma resumida toda la información económica para su análisis e interpretación.

El estado de resultados, considera tres elementos: (a) ingresos, que incluyen flujos o entradas de recursos incrementando el patrimonio, los mismos que son obtenidos por las ventas de acuerdo a la actividad del ente durante un periodo, (b) los costos, constituidos por compromisos asociados a la adquisición o elaboración de los bienes por los que obtuvo los ingresos, y (c) los gastos, que reflejan el egreso de dinero, disminuyendo el patrimonio diferente a retiro de capital o de utilidades, éstos se generan en áreas administrativas y de comercialización. Este estado por medio de la utilidad neta, mide los resultados obtenidos de la actividad empresarial durante un periodo, además permite evaluar la rentabilidad del ente económico, acceso a créditos, identificación de riesgos y distribución de dividendos. Para Palomares y Peset (2015) es también llamado estado de pérdidas y ganancias, e indica las entradas y egresos de un ejercicio contable por lo regular de un año; su estructura está 
compuesta por ingresos y gastos por su función (producción, comerciales, administración) y por su naturaleza (explotación, financieros, etc.).

Illescas (2012) y Moreno (2013) coinciden que el estado de cambios en el patrimonio indica las variaciones del capital en un periodo concreto, si existe utilidades retenidas y utilidad neta, así también si se han cancelado los dividendos a los accionistas. Estupiñán (2017) menciona que este estado debe contener: el resultado del ejercicio, cuentas de ingresos y gastos que se hayan identificado de manera directa en el patrimonio y su total, totalidad de ingresos y gastos del periodo atribuible a los propietarios de patrimonio neto.

El estado de flujos de efectivo, puede presentarse utilizando: el método directo, separado por categorías de cobros y pagos en términos brutos o, el método indirecto, de partidas de ingreso o gasto asociadas con flujos de efectivo, por operaciones de inversión (propiedad, planta y equipo, activos permanentes o no corrientes) o financiación (financiaciones externas, movimientos de cuentas patrimoniales externas). En su elaboración se consideran los flujos de efectivo de los movimientos de operación, en las entradas se detalla lo recibido en efectivo por comercialización de bienes o prestación de servicios, cobros de cuentas, cobro de intereses; $y$, en las salidas de efectivo se describe los desembolsos de efectivo por las compras de materiales, insumos o bienes para la venta, cancelaciones de cuentas a proveedores, empleados, intereses y otros egresos no afines con movimientos de inversión y financiamiento (ibídem).

Por otra parte, Carvalho (2009) menciona que las notas aclaratorias a los estados financieros, son necesarias para demostrar la revelación completa de la información de la entidad, ayudando a la comprensión y análisis de la situación económica. Con la finalidad de explicar o aclarar dudas, las notas se colocan en cada estado financiero elaborado, para su identificación se emplea letras o números demostrando lógica en su presentación, despejando dudas acerca de valores o hechos que afectan al periodo presente o de un periodo a otro y fundamentándose en los principios de contabilidad. Para Estupiñán (2017) las notas a los estados financieros deben presentar: información sobre la preparación de estados financieros y qué políticas contables se aplicó para su elaboración, desglose de la información requerida por las Normas Internacionales de Información Financiera (NIIF) no presentada en los balances, además debe proporcionar información adicional que sea relevante para comprender los balances.

Es preciso señalar que, a la par de la utilización de los estados financieros y la aplicación de las normas internacionales de información financieras hoy por hoy la tributación se ha 
convertido en uno de los principales aspectos a considerar en la economía y en el manejo de una empresa o actividad, por lo que se ha creído conveniente abarcar temas trascendentales de esta rama.

Ámez (2002) menciona que el impuesto constituye una contribución, obligación o exigencia que el Estado impone a los contribuyentes, para conseguir ingresos que ayuden a financiar los llamados servicios públicos indivisibles o necesidades colectivas, se basa en una cadena de elementos impositivos teniendo como finalidad la obtención de algunos objetivos básicos, como la repartición equitativa de los mismos y el logro de metas económicas o de eficiencia administrativa. Se considera a los impuestos como contribuciones obligatorias, estableciendo una relación legal entre el estado y la ciudadanía, mediante el pago que realizan las personas naturales y sociedades por el precio de vivir en sociedad. En la actualidad los impuestos son considerados el rubro de mayor importancia dentro del presupuesto general del estado por su alto nivel recaudatorio, apoyándose en principios de equidad. En tal contexto, en las transacciones de compra-venta se debe cumplir con el cobro y retención de impuestos para su posterior declaración y pago en los plazos establecidos por el SRI, los cuales se mencionan a continuación:

(a) Retención y declaración mensual del impuesto al valor agregado (IVA)

Goxens y Goxens (2000) señalan que el IVA es un tributo indirecto establecido por ley, que recae en el consumidor por el pago de un bien o prestación de servicios dentro del ámbito de las actividades empresariales o profesionales, así como en las importaciones de bienes, siendo el servicio nacional de aduana del Ecuador el responsable de liquidar el IVA en las importaciones. En el caso de importaciones, el IVA pagado en la liquidación de aduana se lo puede deducir del IVA a pagar.

(b) Retención, declaración mensual y anual del impuesto a la renta.

Este impuesto constituye un tributo que se calcula en base a los ingresos obtenidos por los contribuyentes, producto de sus actividades económicas durante un año, descontando los costos y gastos en que han incurrido para el cumplimiento de sus operaciones (Balseca, 2012). Las sociedades y contribuyentes obligados a llevar contabilidad realizan su declaración en base a sus estados financieros, en el caso de las personas naturales que ejecuten actividades empresariales que no superen los montos para ser obligados a llevar contabilidad tomarán como base su registro de ingresos y egresos. 


\section{Teorías y principios aduaneros.}

Como estrategia para motivar el consumo de productos nacionales ante la oferta de productos importados, el gobierno ecuatoriano estableció tributos a pagar en caso de ingresar mercaderías del exterior, evitando la salida de divisas del país. A pesar de esta normativa, al existir productos que no se puede encontrar a nivel nacional como es el caso de repuestos de maquinaria pesada, es necesario recurrir a las importaciones. En tal contexto, las mercaderías, medios de transporte que pasan la frontera y quienes realicen actividades directa o indirectamente vinculadas con el tráfico internacional de mercancías, están sometidos a la autoridad aduanera, situación que implica el cumplimiento de todas las formalidades y requisitos que regulen el ingreso y egreso de personas, mercancías, cancelación de los tributos y otras cargas exigibles con la documentación correspondiente en los plazos determinados por ley. De igual manera, es necesario recurrir a la nacionalización, considerada por Estrada (2012) como el ciclo por el cual las mercancías de otros países ya ingresadas al país se legitiman por medio del pago de impuestos, es decir se reconocen como ecuatorianas, luego de presentada la declaración y realización de los pagos respectivos de impuestos.

Para realizar el proceso de importación se debe seguir una serie de procedimientos: inicialmente debe inscribirse como importador para obtener la clave de acceso, presentar una solicitud a la SENAE conjuntamente con copia del documento de ciudadanía, copia del registro único de contribuyentes (RUC), adjuntar cotización del vendedor en la que constan los productos con precios y condiciones de venta acompañada de orden de pedido hecha por el fabricante o proveedor, así mismo se debe contratar una póliza de seguro que puede ser a una entidad nacional de seguros o un bróker extranjero domiciliado en el país, posteriormente se realiza declaración aduanera de valor (DAV) obligatoria para la ejecución de la importación y finalmente la declaración aduanera única (DAU) presentada electrónicamente por parte del funcionario afianzado de aduanas.

Según la Asamblea Nacional Constituyente (2019) respecto de la base imponible en bienes importados en el Art. 59 de la Ley Orgánica de Régimen Tributario Interno indica que la base imponible en las importaciones, es el resultado de sumar al valor en aduana los impuestos (que no sean recuperables posteriormente de las autoridades fiscales), aranceles, tasas, derechos, recargos y otros gastos que se indiquen conformen en la declaración de importación.

La Asamblea Nacional Constituyente (2019) en el Código Organico de la Producción, Comercio e Inversiones en el Art. 110 establece. - Base imponible. - es el valor en aduana de 
las mercancías importadas, conformado por el valor de las transacciones más los costos del transporte y seguro. El costo del seguro constituirá parte del valor en aduana, pero la póliza de seguro no será documento obligatorio de soporte exigible a la declaración aduanera. En caso de no poder determinar la base imponible, respecto al valor de las mercancías importadas, se establecerá de acuerdo a los métodos secundarios de evaluación los cuales son: valor de transacción de mercaderías idénticas o similares, método deductivo, método de valor reconstruido y método de última instancia, previstos en las normas que regulan el valor en aduana de mercancías. Para establecer la base imponible, los valores indicados en moneda extranjera, serán transformados a la moneda de uso legal, al tipo de cambio vigente a la fecha de la presentación de la declaración aduanera.

Por lo expuesto anteriormente, con la finalidad de garantizar que el proceso contable, tributario y aduanero se ejecute de manera eficiente, resulta vital contar con procedimientos que guíen el cumplimiento de las diferentes operaciones; por lo general éstos se realizan en base a conocimientos y experiencias en función del tipo de actividad a desarrollarse, por tanto, si cada integrante de la empresa conoce los manuales de procedimientos, ciertamente su trabajo será satisfactorio, lo contrario ocurrirá si no se lo hace. Cabe mencionar que, estos procedimientos se pueden ir actualizando y mejorando en base a estudios y a los resultados obtenidos de los procesos ya existentes.

Para el desarrollo de los procedimientos es importante la elaboración de diagramas de flujo, los cuales constituyen una herramienta de fácil comprensión porque clarifican y guían el accionar de los empleados en cada etapa, incrementando la inclusión del personal en el logro de los objetivos empresariales.

\section{Metodología.}

La presente investigación se desarrolló bajo el enfoque mixto, predominando el método cualitativo en la revisión de la literatura y elaboración del marco teórico, y en menor predominio el método cuantitativo en la fase de diagnóstico. La investigación se enmarcó en un enfoque descriptivo-explicativo secuencial (DEXPLIS), utilizado en la revisión de la literatura especializada en el tema, así como en la interpretación de resultados obtenidos mediante las técnicas de revisión documental y aplicación de encuestas a los directivos y trabajadores relacionados directamente con los procesos de importación.

La investigación se desarrolló con dos universos de estudio, el primero con el total del personal involucrado en los procedimientos contables, tributarios y aduaneros de la empresa 
Tracto Oruga (Tabla 1), y el segundo por 38 registros de compras realizadas a través de importaciones

Tabla 1. Población

\begin{tabular}{cll}
\hline \multirow{1}{*}{ Empresa } & \multicolumn{1}{c}{ Área } & N. Personas \\
\hline \multirow{4}{*}{ Tracto Oruga } & Gerencia & 1 \\
\cline { 2 - 3 } & Contabilidad & 3 \\
\cline { 2 - 3 } & Crédito y cobranzas & 1 \\
\cline { 2 - 3 } & Ventas & 2 \\
\cline { 2 - 3 } & Encargado de ingresar compras & 1 \\
\cline { 2 - 3 } & Bodega & 2 \\
\hline
\end{tabular}

Tabla 2. Transacciones de importación.

\begin{tabular}{cccc}
\hline Empresa & Transacciones & $\begin{array}{c}\text { No. registros de } \\
\text { importaciones }\end{array}$ & Total \\
\hline Tracto Oruga & Importaciones 2018 & 38 & 38 \\
\hline & & & $\mathbf{3 8}$ \\
\hline
\end{tabular}

\section{Resultados.}

Los principales resultados obtenidos de la fase de diagnóstico en la empresa Tracto Oruga de la ciudad de Loja, se presentan a continuación de forma sintetizada:

- Deficiente registro de la información contable, debido a la falta de documentación de respaldo durante los procesos de importación.

- Estimación de precios de venta de forma inadecuada por falta de información de los costos reales incurridos en la etapa de importación de los repuestos.

- Deficiencia en las relaciones con proveedores del exterior en vista de que los precios que inicialmente se proforman difieren al momento de efectivizar la compra, afectando al precio de venta por las variaciones en el costo y por ende a la utilidad estimada.

- Inadecuado control en cada uno de los procesos durante las importaciones, impidiendo tener la información de manera correcta y oportuna, afectando a la deducibilidad tributaria del costo asignado.

- Presentación tardía de estados financieros, imposibilitando la toma de decisiones y correctivos oportunos ante posibles amenazas. 
A partir de estos resultados se proponen los siguientes procedimientos contables, tributarios y aduaneros para la empresa Tracto Oruga

\section{Estructura Interna.}

El proceso contable que se lleva a cabo actualmente en la empresa Tracto Oruga se fundamenta en una estructura organizacional básica, frente a ello se propone una nueva estructura funcional dividida en departamentos, con la finalidad de que exista una correcta distribución jerárquica y detalle de funciones (figura 1), además, resulta imperiosa la necesidad de establecer objetivos para cada función, siendo de ayuda en la realización de actividades y aportando en la toma asertiva de decisiones empresariales.

Figura 1. Organigrama actual vs Organigrama estructura funcional

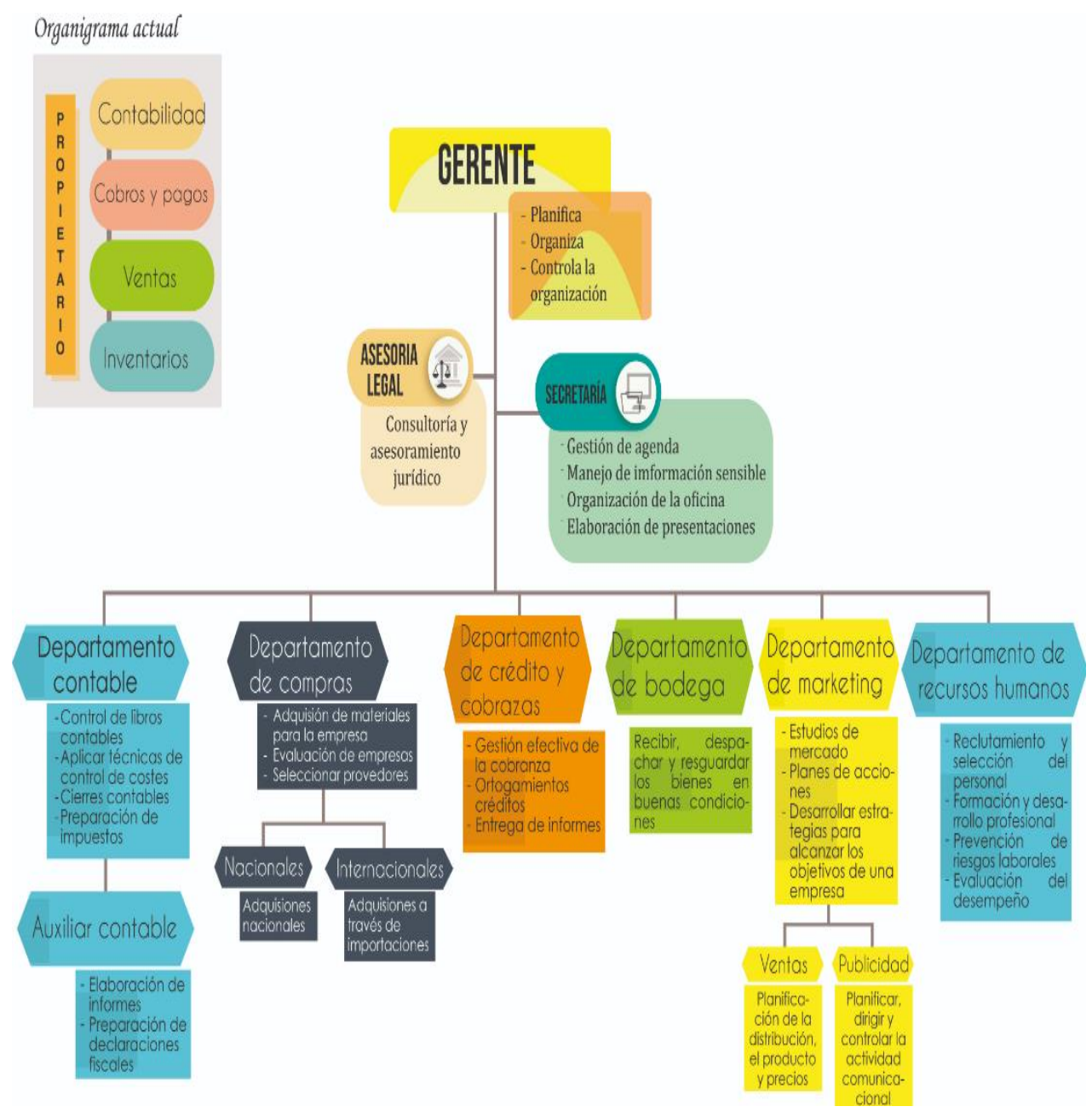




\section{Políticas contables, tributarias y aduaneras aplicadas a las importaciones.}

Las políticas contables, tributarias y aduaneras que intervienen en el proceso de importación y que rigen para la empresa Tracto Oruga deben cumplir con la normativa vigente establecidas por las normas internacionales de contabilidad, normas internacionales de información financiera para pymes, SRI y SENAE.

A continuación de manera general y específica se muestra por medio de tablas, figuras, flujogramas y asientos contables los procedimientos contables y tributarios que se propone para las importaciones de la empresa Tracto Oruga.

Tabla 3. Ficha general de procedimientos.

\begin{tabular}{|c|c|c|}
\hline Procedimiento & Funciones & Objetivos \\
\hline \multirow{7}{*}{ Gerencia } & Planificar objetivos empresariales. & \multirow{7}{*}{$\begin{array}{l}\text { Planificar, organizar, } \\
\text { dirigir, controlar, } \\
\text { coordinar, analizar, } \\
\text { calcular y deducir el } \\
\text { trabajo de la empresa. }\end{array}$} \\
\hline & Organizar los materiales y aprovechar los recursos disponibles. & \\
\hline & Establecer y negociar contratos ante entes públicos y privados. & \\
\hline & $\begin{array}{l}\text { Representar a la empresa ante las autoridades judiciales, } \\
\text { administrativas, laborales. }\end{array}$ & \\
\hline & $\begin{array}{l}\text { Celebrar contratos de compraventa internacional, y demás } \\
\text { relacionados con el comercio exterior, tales como importaciones. }\end{array}$ & \\
\hline & $\begin{array}{l}\text { Controlar y supervisar las funciones de cada trabajador de la } \\
\text { empresa. }\end{array}$ & \\
\hline & Ordenar y autorizar pagos. & \\
\hline \multirow{5}{*}{ Ventas } & Servicio al cliente. & \multirow{5}{*}{$\begin{array}{l}\text { Brindar servicio y } \\
\text { atención de calidad a } \\
\text { todos los clientes. }\end{array}$} \\
\hline & Venta de mercadería a precios establecidos. & \\
\hline & Facturar productos vendidos. & \\
\hline & Llevar un adecuado control de pedidos y de ventas realizadas. & \\
\hline & $\begin{array}{l}\text { Entregar de manera oportuna la documentación generada al } \\
\text { departamento contable para su correspondiente registro. }\end{array}$ & \\
\hline \multirow{2}{*}{$\begin{array}{l}\text { Crédito y } \\
\text { cobranzas }\end{array}$} & $\begin{array}{l}\text { Análisis de cuentas para otorgamiento de los créditos y } \\
\text { verificación de documentos entregados por los deudores. }\end{array}$ & \multirow{2}{*}{$\begin{array}{l}\text { Recuperación eficiente } \\
\text { de ventas a crédito y } \\
\text { revisión de facturas de } \\
\text { proveedores, } \\
\text { determinando } \\
\text { aprobación o rechazo. }\end{array}$} \\
\hline & $\begin{array}{l}\text { Registro inmediato de cobros y pagos en el sistema contable } \\
\text { correspondiente, luego de verificar minuciosamente la } \\
\text { documentación. }\end{array}$ & \\
\hline
\end{tabular}


Informar a gerencia sobre los créditos solicitados, montos y su aceptación o negación.

Cuentas por pagar, revisión y emisión de cheques con autorización.

Entrega de reportes mensuales de cuentas por cobrar y pagar, al término de cada mes al departamento de contabilidad.

Verificar el inventario antes de realizar una nueva compra.

Analizar tendencias del mercado y sus precios.

Realizar el proceso correspondiente para compras al exterior de mercadería para

Compras (importaciones). stock y compras

Revisar y verificar envíos de proveedores. específicas por medio Relaciones eficientes con proveedores. de importaciones.

Laborar conjuntamente con todas las áreas de la empresa.

Actividades de control de inventarios periódicos.

Verificar los productos al recibir y entregar.

Diligenciar los documentos necesarios que respalden lo recibido y despachado.

Administrar correctamente las bodegas con los

Revisar deficiencias (empaques dañados, faltantes, sobrantes), el adecuado almacenaje del producto en bodega. productos de propiedad de la empresa.

Verificar los documentos de despacho (facturas y notas de entrega).

Revisión y análisis de la documentación para realizar el registro contable.

Elaborar los asientos contables de forma ordenada.

Elaborar procedimientos de la Declaraciones mensuales y anual SRI. gestión financiera por

Contabilidad

Valoración de costos, gastos e ingresos de importación. medio de registros

Entrega de estados financieros. contables hasta la presentación de estados financieros.

Supervisar y revisar el trabajo realizado por auxiliares contables. 
Figura 2. Flujograma general importaciones

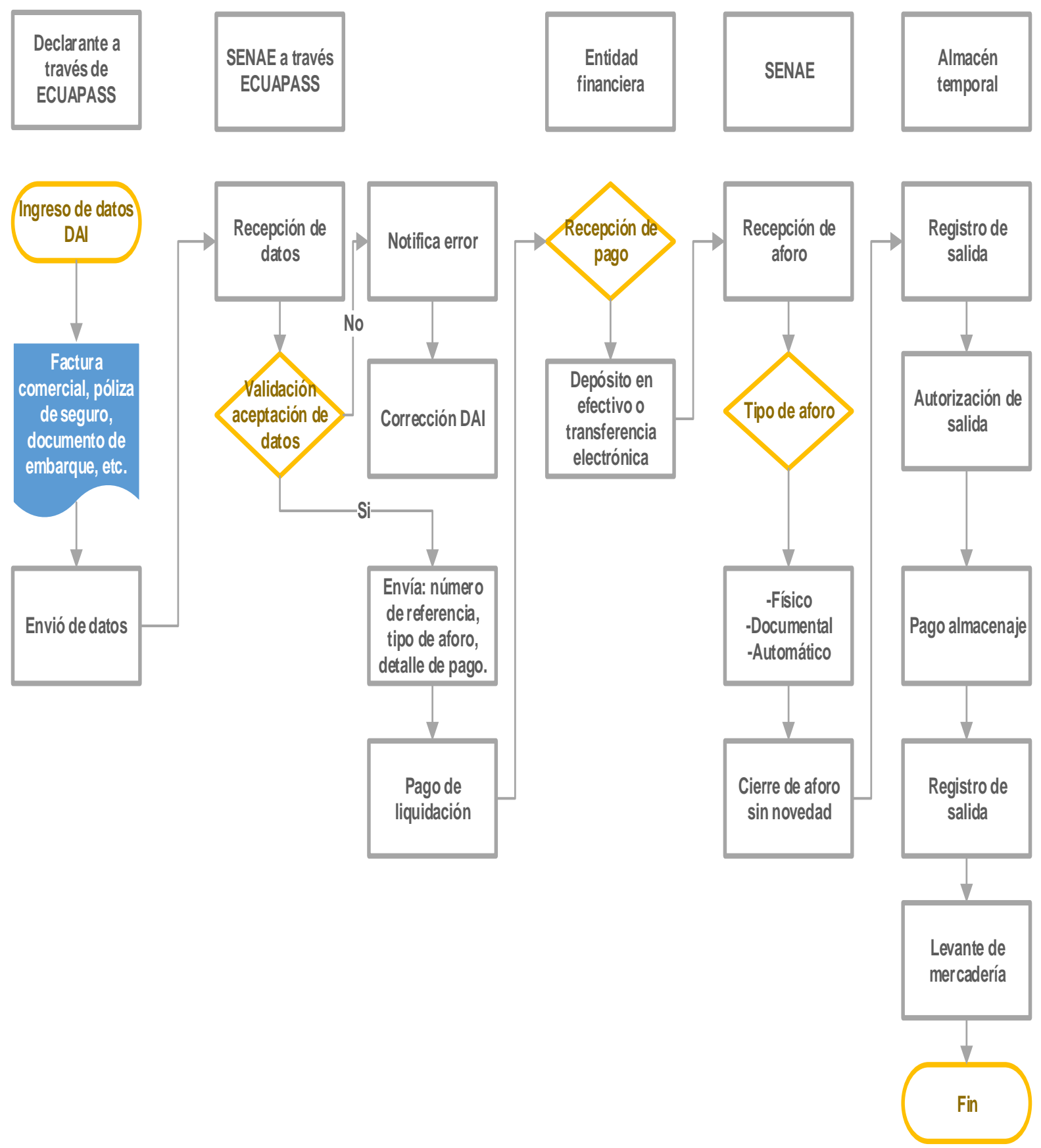


Figura 3. Mapeo de procesos de importación Tracto Oruga

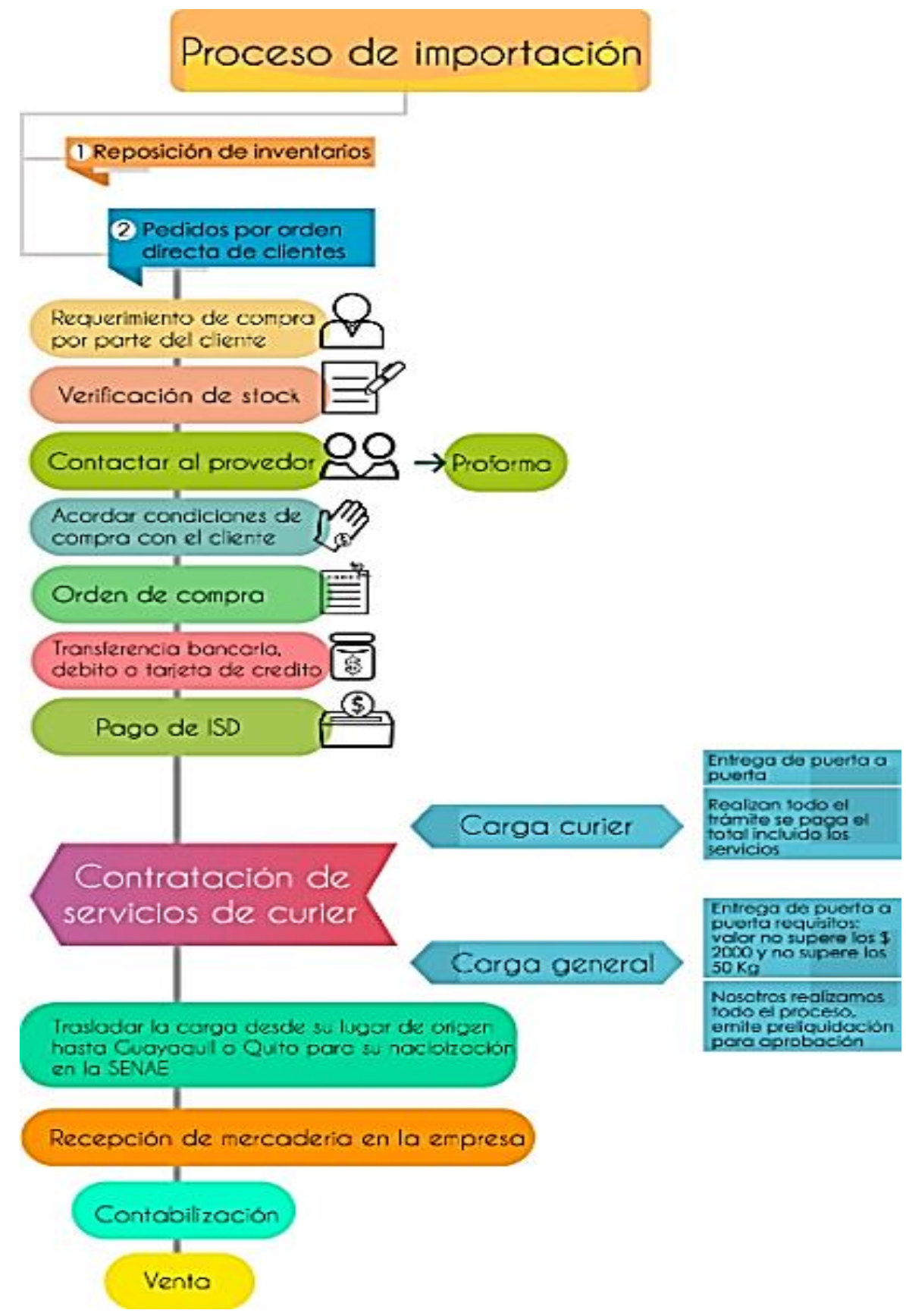


Figura 4 Flujograma de reposición de inventario

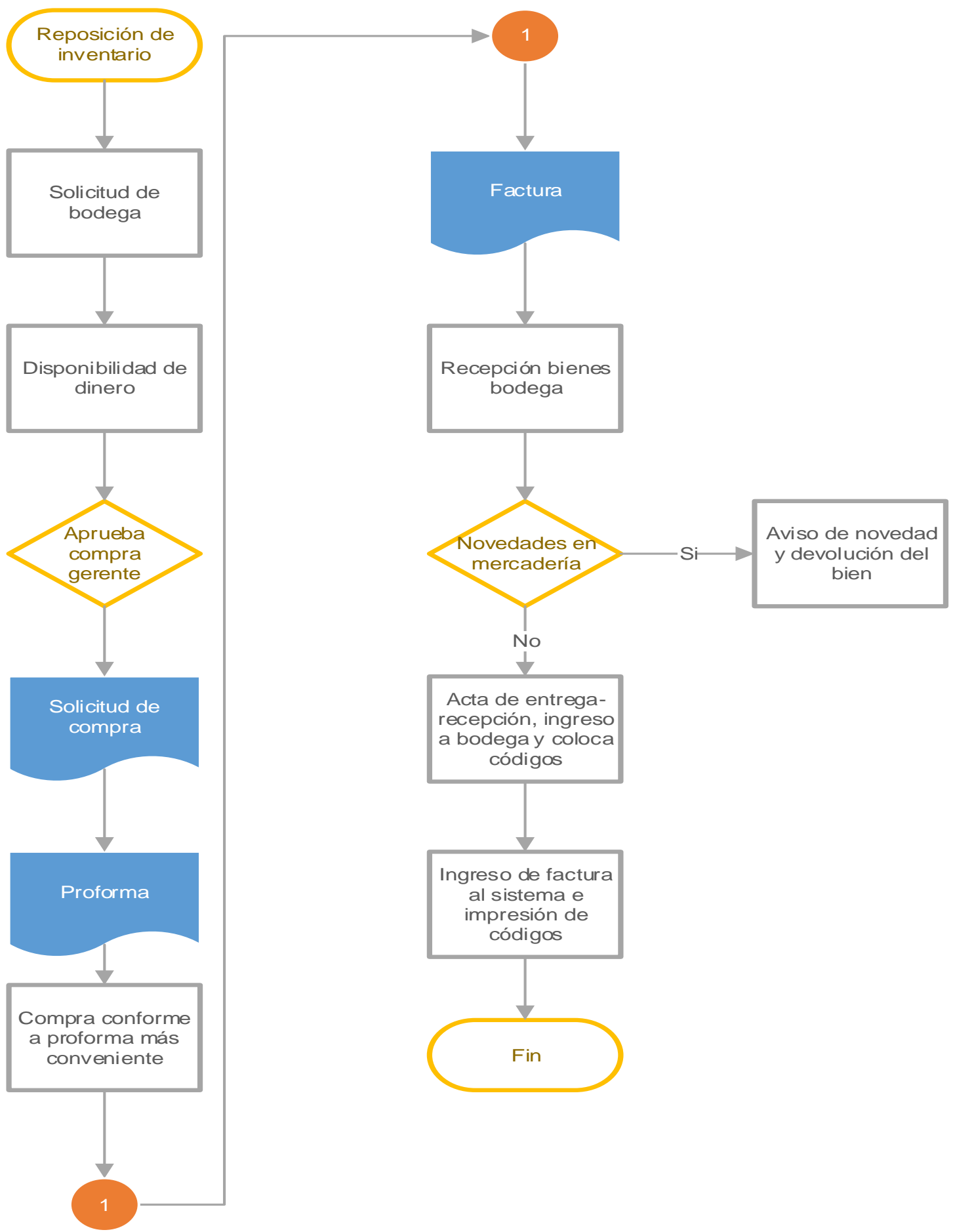


Tabla 4. Procedimientos contables y tributarios.

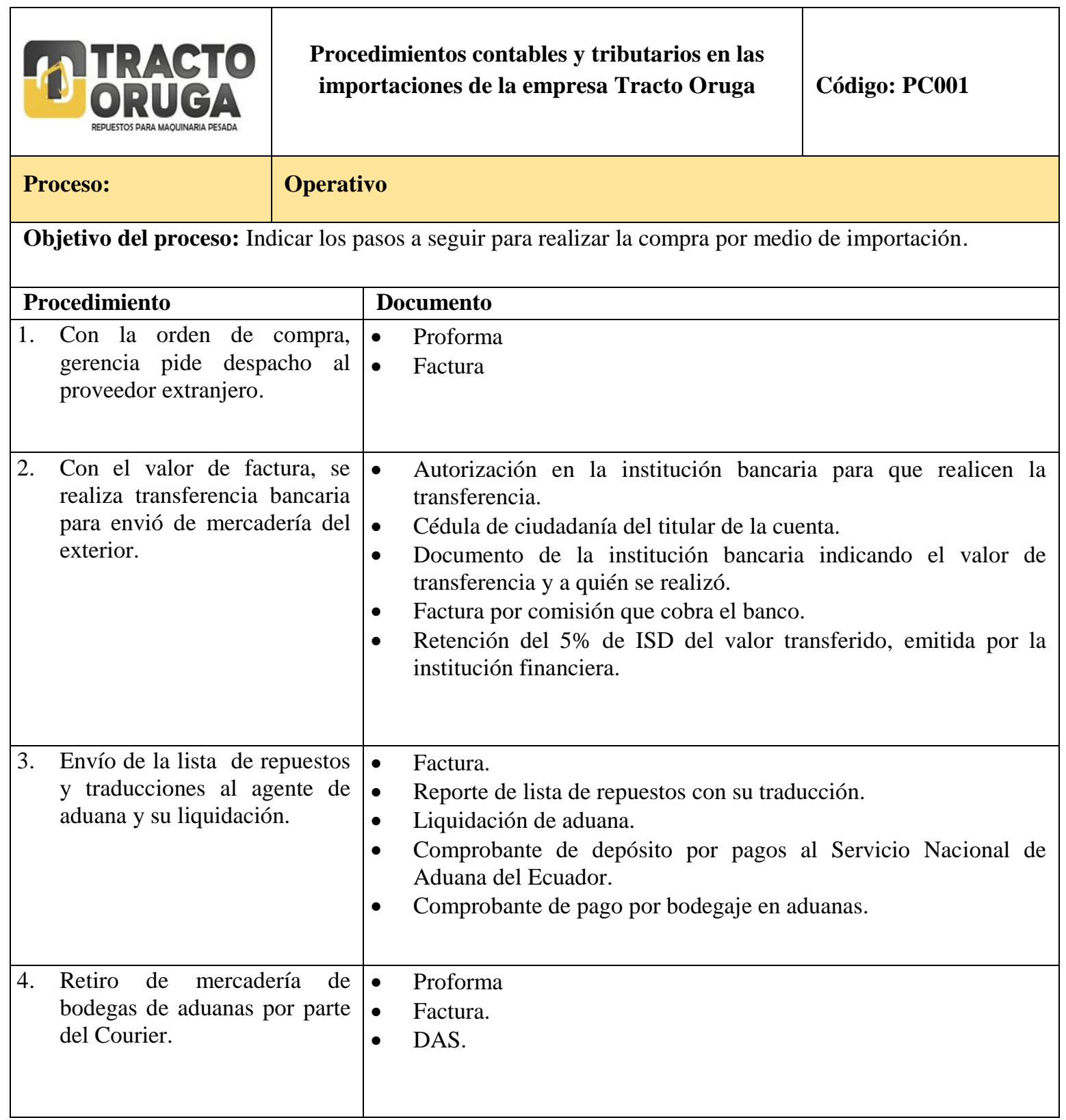


Tabla 5. Procedimientos contables y tributarios.

\begin{tabular}{|c|c|c|}
\hline $\begin{array}{r}\text { Proc } \\
\text { imp }\end{array}$ & $\begin{array}{l}\text { Procedimientos contables y tributarios en las } \\
\text { importaciones de la empresa Tracto Oruga }\end{array}$ & Código: PC001 \\
\hline Proceso: & \multicolumn{2}{|c|}{ Contable y tributario } \\
\hline \multicolumn{3}{|c|}{ Objetivo del proceso: Indicar los pasos a seguir para el registro y contabilización de la importación. } \\
\hline Procedimiento & \multicolumn{2}{|l|}{ Documento } \\
\hline $\begin{array}{l}\text { 1. Lista de todos los costos y } \\
\text { gastos incurridos en la } \\
\text { importación. }\end{array}$ & \multicolumn{2}{|c|}{$\begin{array}{l}\text { - Facturas de courier por gastos logísticos. } \\
\text { - Facturas de bodegaje. } \\
\text { - Liquidación de aduana con detalle de los impuestos } \\
\text { cancelados. }\end{array}$} \\
\hline $\begin{array}{l}\text { 2. Ingreso al sistema contable de } \\
\text { todos los productos } \\
\text { importados al costo unitario } \\
\text { obtenidos del paso } 1 .\end{array}$ & \multicolumn{2}{|c|}{ - $\quad$ Reporte contable con el detalle de los productos y costos. } \\
\hline $\begin{array}{l}\text { 3. Registro de asiento contable de } \\
\text { la compra y de pagos } \\
\text { efectuados. }\end{array}$ & \multicolumn{2}{|c|}{ 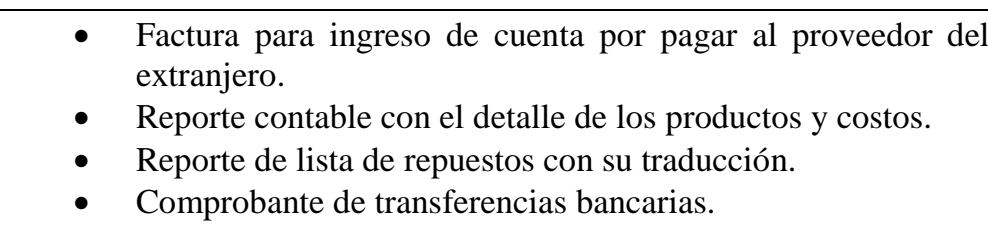 } \\
\hline \begin{tabular}{|ll} 
4. & $\begin{array}{l}\text { Asignación de precios de } \\
\text { venta. }\end{array}$ \\
\end{tabular} & \multicolumn{2}{|c|}{ - $\quad$ Detalle del costo de cada producto importado. } \\
\hline
\end{tabular}

\section{Políticas contables}

- Efectivo y equivalentes de efectivo

Todos los pagos superiores a mil dólares se los realizará con utilización del sistema bancario, en los casos que los proveedores sean recurrentes los pagos se los realizará mediante cheque o transferencia sin excepción, caso contrario se los efectuará en efectivo.

Dinámica de la cuenta

Debita: al momento que existe la venta en efectivo, recaudación de cuentas por cobrar o acreditación de créditos bancarios. Y se acredita: por pago de una cuenta pendiente, depósito en efectivo en las cuentas bancarias, entrega de un anticipo o para realizar una compra sea esta de inventario, compra de un activo o pago por factura de gastos incurridos para el desarrollo de las actividades. 
Tabla 6. Asiento de efectivo y equivalentes de efectivo

\begin{tabular}{|c|c|c|c|c|}
\hline Fecha & Código de cuenta & Detalle o descripción & Debe & Haber \\
\hline & 1.01 .01 .01 .01 & Caja general & $\mathrm{xxx}$ & \\
\hline & 1.01 .01 .03 .01 & Venta neta locales de bienes & & $\mathrm{xxx}$ \\
\hline & 2.01.01.02.04.01.08 & I.V.A Ventas & & $\mathrm{xxx}$ \\
\hline & & $\begin{array}{l}\text { Por venta en efectivo a Sr. xxx según factura } \\
3524 \text {. }\end{array}$ & & \\
\hline
\end{tabular}

Tabla 7. Asiento depósito en cuenta corriente Banco de Loja.

\begin{tabular}{|c|c|c|c|c|}
\hline Fecha & Código de cuenta & Detalle o descripción & Debe & Haber \\
\hline & 1.01 .01 .01 .01 & Banco de Loja & $\mathrm{xxx}$ & \\
\hline & 1.01.01.01.01 & Caja general & & $\mathrm{xxx}$ \\
\hline
\end{tabular}

Por depósito en efectivo en cuenta corriente Banco de Loja, ref. 1025846.

La cuenta de efectivo, actualmente agrupa pagos inmediatos realizados a proveedores, esta cuenta se la debería utilizar en pagos mínimos y con proveedores no habituales ya que en caso de serlo y superar el monto de 1000.00 dólares se debe realizar a través del sistema bancario.

- Inventario

Los inventarios constituyen la mercadería ingresada por las compras nacionales e internacionales a su precio de costo, son valuadas por el sistema de cuenta permanente o inventario perpetuo.

Dinámica de la cuenta

Esta cuenta se debita al momento de realizar la compra ya sea nacional o del exterior y se acredita cuando ocurre la venta.

Tabla 8. Compras inventario en tránsito.

\begin{tabular}{lllcr}
\hline Fecha & \multicolumn{1}{c}{ Código de cuenta } & \multicolumn{1}{c}{ Detalle o descripción } & Debe & Haber \\
\hline 1.01 .07 .01 .01 & Compras de inventarios en tránsito & $\mathrm{xxx}$ & \\
\hline 1.01 .06 .01 .02 & I.V.A compras bienes/servicios & $\mathrm{xxx}$ & \\
\hline 2.01 .01 .02 .04 .01 .01 & Retención 1\% IR por pagar & $\mathrm{xxx}$ \\
\hline 1.01 .01 .03 .01 & \multicolumn{1}{c}{ Banco de Loja/ efectivo } & $\mathrm{xxx}$ \\
\hline & $\begin{array}{l}\text { Por compra de mercadería a proveedor xxx } \\
\text { factura 7589, se cancela con transferencia } \\
584936 \text { Banco de Loja. }\end{array}$ & \\
\hline
\end{tabular}


Tabla 9. Inventario compra nacional

\begin{tabular}{cclcc}
\hline Fecha & Código de cuenta & \multicolumn{1}{c}{ Detalle o descripción } & Debe & Haber \\
\hline 1.01 .07 .04 .01 & $\begin{array}{l}\text { Inventarios productos terminados y mercadería en } \\
\text { almacén }\end{array}$ & $\mathrm{xxx}$ & \\
\hline 1.01 .06 .01 .02 & \multicolumn{1}{c}{ Compras de inventarios en tránsito } & $\mathrm{xxx}$ \\
\hline & $\begin{array}{l}\text { Por compra de inventario a proveedor xxx factura } \\
7589, \text { se cancela con transferencia 584936 Banco de } \\
\text { Loja. }\end{array}$ & \\
& & \\
&
\end{tabular}

Compras internacionales:

Precio $\mathrm{FOB}^{4}: \quad \mathrm{xxx}$

Precio flete: $\quad \mathrm{xxx}$

FODINFA $5: \quad \quad x x x$

Manejo de carga: $\quad \underline{\mathrm{xxx}}$

Total compras $\quad \mathrm{xxx}$

Tabla 10. Compras inventario en tránsito al exterior.

\begin{tabular}{lllcc}
\hline Fecha & \multicolumn{1}{c}{ Código de cuenta } & \multicolumn{1}{c}{ Detalle o descripción } & Debe & Haber \\
\hline 1.01 .07 .01 .01 & Compras de inventarios en tránsito & $\mathrm{xxx}$ & \\
\hline 1.01 .06 .01 .02 & I.V.A compras bienes/servicios & $\mathrm{xxx}$ & \\
\hline 1.01 .01 .03 .01 & \multicolumn{1}{c}{ Banco de Loja/ efectivo } & & $\mathrm{xxx}$ \\
\hline & $\begin{array}{l}\text { Por compra de mercadería a proveedor xxx } \\
\text { factura 7589 y liquidación aduanera 547995, se } \\
\text { cancela con transferencia 584936 Banco de } \\
\text { Loja. }\end{array}$ & & \\
& & & \\
\end{tabular}

Tabla 11. Inventario compra al exterior.

\begin{tabular}{ccccc}
\hline Fecha & Código de cuenta & \multicolumn{1}{c}{ Detalle o descripción } & Debe & Haber \\
\hline 1.01 .07 .04 .01 & $\begin{array}{l}\text { Inventarios productos terminados y mercadería } \\
\text { en almacén }\end{array}$ & $\mathrm{xxx}$ & \\
\hline 1.01 .06 .01 .02 & \multicolumn{1}{c}{ Compras de inventarios en tránsito } & $\mathrm{xxx}$ \\
\hline & $\begin{array}{l}\text { Por compra de inventario a proveedor xxx } \\
\text { factura 7589, se cancela con transferencia } \\
584936 \text { Banco de Loja. }\end{array}$ & \\
\hline
\end{tabular}

Las compras de inventario se realizan a proveedores del país y proveedores del exterior, su registro contable se lo ejecuta por medio del sistema de cuenta permanente o inventario perpetuo, en compras nacionales se aplica la respectiva retención en la fuente y de IVA si

\footnotetext{
${ }^{4}$ FOB: Incoterm, el comprador asume los costos desde el punto de embarque

${ }^{5}$ FODINFA: fondo de desarrollo para la infancia
} 
corresponde, en caso de importaciones no se elabora retención en las compras, se registra la liquidación aduanera en la que constan los detalles de las facturas de los proveedores del exterior, incluyendo todos los costos en los que se incurrió para efectuar la compra.

- Anticipo a proveedores

Se considerarán los pagos efectuados a proveedores realizados en efectivo o con utilización del sistema bancario para reservar una compra futura ya sea en el país o en el exterior, se deberá emitir el correspondiente comprobante para constancia de lo entregado o la transacción y correo de confirmación en caso de anticipos para importaciones.

Dinámica de la cuenta

Esta cuenta se debita al momento que se realiza el anticipo, y se acredita en el momento de que se efectúa la compra y se recibe la importación.

Tabla 12. Entrega de anticipo a proveedores

\begin{tabular}{lcccc}
\hline Fecha & Código de cuenta & Detalle o descripción & Debe & Haber \\
\hline 1.01 .02 .02 .04 .01 & Anticipo a proveedores & $\mathrm{xxx}$ & \\
\hline 1.01 .01 .03 .01 & Banco de Loja & $\mathrm{xxx}$ & \\
\hline & $\begin{array}{l}\text { Por transferencia del Banco de Loja a proveedor } \\
\text { xxx para compra según factura 7589. }\end{array}$ & \\
\hline
\end{tabular}

Tabla 13. Utilización de anticipo.

\begin{tabular}{ccccc}
\hline Fecha & Código de cuenta & \multicolumn{1}{c}{ Detalle o descripción } & Debe & Haber \\
\hline 2.01 .01 .01 .02 .01 & $\begin{array}{l}\text { Cuentas y documentos por pagar proveedores } \\
\text { no relacionados exterior }\end{array}$ & xxx \\
\hline 1.01 .02 .02 .04 .01 & Anticipo a proveedores & xxx \\
\hline & $\begin{array}{l}\text { Por pago a proveedor x por la compra según } \\
\text { factura 7589 se hace cruce con efectivo } \\
\text { realizado, transferencia Banco de Loja. }\end{array}$ & \\
& &
\end{tabular}

Tabla 14. Devolución de anticipo

\begin{tabular}{ccccc}
\hline Fecha & Código de cuenta & \multicolumn{1}{c}{ Detalle o descripción } & Debe & Haber \\
\hline 1.01 .01 .03 .01 & Banco de Loja & xxx & \\
\hline 1.01 .02 .02 .04 .01 & \multicolumn{1}{c}{ Anticipo a proveedores } & \\
\hline & $\begin{array}{l}\text { Por devolución de anticipo porque no se realizó } \\
\text { la compra por no cumplir los tiempos } \\
\text { establecidos. }\end{array}$ & \\
\hline
\end{tabular}


Los anticipos se realizan cuando son proveedores nuevos y aun no se tiene la respectiva factura, se debe descontar el valor de la retención y transferir el saldo real a pagar.

- Cuentas por pagar

Valores pendientes de cancelar por adquisiciones a crédito sea por compras de inventario, servicios o gastos, se deberá tener la constancia y archivo de los documentos de respaldo de dichas cuentas, se considerará las fechas plazo otorgadas por los proveedores en los casos que sea necesario para su respectivo pago.

Dinámica de la cuenta

Se debita por pagos totales o abonos realzados y se acredita por el valor de compromisos obtenidos.

Tabla 15. Cuentas por pagar

\begin{tabular}{|c|c|c|c|c|}
\hline Fecha & Código de cuenta & Detalle o descripción & Debe & Haber \\
\hline & 1.01.07.01.01 & Compras de inventarios en tránsito & $\mathrm{xxx}$ & \\
\hline & 1.01 .06 .01 .02 & I.V.A compras bienes/servicios & $\mathrm{xxx}$ & \\
\hline & 2.01 .01 .02 .04 .01 .01 & Retención $1 \%$ IR por pagar & & $\mathrm{xxx}$ \\
\hline & 2.01 .01 .01 .02 .01 & $\begin{array}{l}\text { Cuentas y documentos por pagar } \\
\text { proveedores no relacionados exterior }\end{array}$ & & $\mathrm{xxx}$ \\
\hline & & $\begin{array}{l}\text { Pr compra de mercadería a proveedor xxx } \\
\text { factura } 7589 \text {, a crédito a } 30 \text { días plazo. }\end{array}$ & & \\
\hline
\end{tabular}

Tabla 16. Cuentas por pagar

\begin{tabular}{|c|c|c|c|c|}
\hline Fecha & Código de cuenta & Detalle o descripción & Debe & Haber \\
\hline & 2.01 .01 .01 .02 .01 & $\begin{array}{l}\text { Cuentas y documentos por pagar proveedores no } \\
\text { relacionados exterior }\end{array}$ & $\mathrm{xxx}$ & \\
\hline & 1.01.07.01.01 & Banco de Loja/Caja general & & $\mathrm{xxx}$ \\
\hline & & $\begin{array}{l}\text { Por pago a proveedor xxx con transferencia } \\
\text { banco de Loja por la compra de mercadería con } \\
\text { factura } 7589 \text { a crédito a } 30 \text { días plazo. }\end{array}$ & & \\
\hline
\end{tabular}

\section{Políticas tributarias}

- IVA Compras o IVA Pagado

Este impuesto se cancela al proveedor al momento de realizar una compra de inventario o de gasto, en caso de importaciones se cancelará al Servicio Nacional de Aduana del Ecuador (SENAE), este impuesto tendrá un control mensual para cumplir con su respectiva 
declaración tributaria en el formulario de IVA que se encuentra en la página del Servicio de Rentas Internas.

Dinámica de la cuenta

Se debita en la compra de bienes o servicios y se acredita por la devolución en compras, por la liquidación y pago del IVA.

Tabla 17. IVA Compras

\begin{tabular}{|c|c|c|c|c|}
\hline Fecha & Código de cuenta & Detalle o descripción & Debe & Haber \\
\hline & 1.01.07.01.01 & Compras de inventarios en tránsito & $\mathrm{xxx}$ & \\
\hline & 1.01 .06 .01 .02 & I.V.A compras bienes/servicios & $\mathrm{xxx}$ & \\
\hline & 2.01.01.02.04.01.01 & Retención $1 \%$ IR por pagar & & $\mathrm{xxx}$ \\
\hline & 2.01 .01 .01 .02 .01 & $\begin{array}{l}\text { Cuentas y documentos por pagar } \\
\text { proveedores no relacionados exterior }\end{array}$ & & $\mathrm{xxx}$ \\
\hline
\end{tabular}

Pr compra de mercadería a proveedor $\mathrm{xxx}$ factura 7589, a crédito a 30 días plazo.

Tabla 18. Neteo de IVA.

\begin{tabular}{lcccc} 
Fecha & Código de cuenta & Detalle o descripción & Debe & Haber \\
\hline 2.01 .01 .02 .04 .01 .08 & I.V.A Ventas & $\mathrm{xxx}$ & \\
\hline 1.01 .06 .01 .02 & I.V.A compras bienes/servicio & $\mathrm{xxx}$ \\
\hline 2.01 .01 .02 .04 .02 .03 & SRI por pagar & $\mathrm{xxx}$ \\
\hline & $\begin{array}{l}\text { Por neteo de IVA y valor a pagar Servicio de } \\
\text { Rentas Internas. }\end{array}$ & \\
\hline
\end{tabular}

- Crédito tributario de IVA

Es el crédito tributario que tiene a favor la empresa cuando el resultado entre el IVA de las compras o pagado, es superior al IVA en ventas o cobrado, este valor se lo deberá utilizar en el mes siguiente en caso de que tuviere valor a pagar, caso contrario si en la declaración de IVA mensual tuviere nuevamente como resultado crédito tributario éste se sumara al crédito existente.

Dinámica de la cuenta

Se debita por retenciones de IVA que nos efectúan los clientes y, se acredita por la diferencia en IVA ventas e IVA compras, si el IVA ventas es mayor, el resultado es un impuesto causado, caso contrario se considera el resultado de crédito tributario para el siguiente mes. 
Tabla 19. Crédito tributario de IVA.

\begin{tabular}{lllcc}
\hline Fecha & Código de cuenta & \multicolumn{1}{c}{ Detalle o descripción } & Debe & Haber \\
\hline 2.01 .01 .02 .04 .01 .08 & I.V.A Ventas & $\mathrm{xxx}$ & \\
\hline 1.01 .06 .01 .01 & Crédito tributario IVA & $\mathrm{xxx}$ & \\
\hline 1.01 .06 .01 .02 & I.V.A compras bienes/servicio & $\mathrm{xxx}$ \\
\hline 2.01 .01 .02 .04 .02 .03 & SRI por pagar & $\mathrm{xxx}$ \\
\hline & $\begin{array}{l}\text { Por neteo de IVA y pago de I.V.A del } \\
\text { mes de xxxx. }\end{array}$ & & \\
\hline
\end{tabular}

- Impuesto a la Renta.

Las importaciones son tomadas en consideración en la declaración de impuesto a la renta, en el rubro de importaciones, al igual que las compras nacionales; está declaración se la realiza de manera anual en el mes de marzo del siguiente año, para cumplir con las obligaciones al fisco.

Dinámica de la cuenta

Se acredita por el pago del impuesto a la renta al final del año y se debita al momento del pago del impuesto a la renta causado en el año.

Tabla 20. Impuesto a la Renta.

\begin{tabular}{ccccc}
\hline Fecha & Código de cuenta & \multicolumn{1}{c}{ Detalle o descripción } & Debe & Haber \\
\hline 3.04 .01 .01 .03 & Pérdidas y ganancias netas del periodo & $\mathrm{xxx}$ & \\
\hline 1.01 .06 .02 .01 & Crédito tributario I.R. años anteriores & $\mathrm{xxx}$ \\
\hline 1.01 .06 .03 .01 & Anticipo de impuesto a la renta & $\mathrm{xxx}$ \\
\hline 2.01 .08 .01 .01 & $\begin{array}{l}\text { Impuesto a la renta por pagar del } \\
\text { ejercicio }\end{array}$ & $\mathrm{xxx}$ \\
\hline 1.01 .06 .03 .02 & Retenciones IR recibidas en ventas & $\mathrm{xxx}$ \\
\hline 2.01 .09 .01 .01 & Participación trabajadores por pagar & $\mathrm{xxx}$ \\
\hline 3.01 .01 .01 .03 & Pérdidas y ganancias netas del periodo & $\mathrm{xxx}$ \\
\hline & $\begin{array}{l}\text { Pr cálculo de utilidad, impuesto a la renta por } \\
\text { pagar y participación a trabajadores. }\end{array}$ & \\
\hline
\end{tabular}

Para registrar el pago al siguiente año:

Tabla 21. Impuesto a la Renta.

\begin{tabular}{ccccc}
\hline Fecha & Código & Detalle o descripción & Debe & Haber \\
\hline 2.01 .08 .01 .01 & Impuesto a la renta por pagar del ejercicio & xxx & \\
\hline 1.01 .07 .01 .01 & Banco de Loja & xxx \\
\hline & Por pago de impuesto a la renta del año 2018. & \\
\hline
\end{tabular}


- Impuesto salida de divisas ISD

Tributo que se cancela por pagos al exterior, el mismo que es retenido al momento de la transferencia o débito bancario al realizar el pago total de la compra o un anticipo a proveedores del exterior. Puede ser tomado como activo, el mismo que nos sirve como crédito tributario para la declaración de impuesto a la renta, o a su vez se lo puede tomar como gasto afectando directamente al Estado de Resultados.

Dinámica de la cuenta

Se debita en el registro del gasto cuando la institución bancaria realiza el débito y se acredita en el cierre del ejercicio.

Tabla 22. Impuesto salida de divisas.

\begin{tabular}{ccccc}
\hline Fecha & Código de cuenta & \multicolumn{1}{c}{ Detalle o descripción } & Debe & Haber \\
\hline 5.08 .13 .01 .09 & Impuesto salida de divisas ISD & xxx & \\
\hline 1.01 .07 .01 .01 & \multicolumn{1}{c}{ Banco de Loja } & xxx \\
\hline & $\begin{array}{l}\text { Pr débito de cuenta corriente Banco de Loja por } \\
\text { pago de impuesto salida de divisas por giro } \\
\text { exterior, ref. 38649. }\end{array}$ & \\
& &
\end{tabular}

\section{Políticas aduaneras.}

CIF: En el documento DAS consta el CIF que comprende el costo, seguro y flete de la mercadería.

En las importaciones se realiza el pago de los siguientes impuestos administrados por la SENAE:

a) Advalorem: pago dependiendo la partida del producto importado y

b) FODINFA: Fondo administrado por el Instituto Público de la Niñez y Adolescencia (INFA) $0.5 \%$ sobre la base imponible.

En los procedimientos de importación se cobra los rubros antes mencionados, los cuales son sumados al costo del inventario o mercadería que se adquiere, estos valores constan en la liquidación de aduana entregada por la SENAE, en esta misma liquidación consta el valor de IVA, todos estos valores se los cancela para que aduana entregue la mercadería.

Tabla 23. Compra de inventario incluido todos los impuestos.

\begin{tabular}{|c|c|c|c|c|}
\hline Fecha & Código de cuenta & Detalle o descripción & Debe & Haber \\
\hline & 1.01.07.01.01 & Compras de inventarios en tránsito & $\mathrm{xxx}$ & \\
\hline & 1.01 .06 .01 .02 & I.V.A compras bienes/servicios & $\mathrm{xxx}$ & \\
\hline & 1.01.01.03.01 & Banco de Loja/ efectivo & & $\mathrm{xxx}$ \\
\hline & & $\begin{array}{l}\text { Pr compra de mercadería a proveedor xxx factura } \\
7589 \text { y liquidación aduanera } 547995 \text {, se cancela } \\
\text { con transferencia } 584936 \text { Banco de Loja. }\end{array}$ & & \\
\hline
\end{tabular}


Tabla 24. Compra de inventario incluido todos los impuestos.

\begin{tabular}{ccccc}
\hline Fecha & Código de cuenta & \multicolumn{1}{c}{ Detalle o descripción } & Debe & Haber \\
\hline 1.01 .07 .04 .01 & $\begin{array}{l}\text { Inventarios productos terminados y mercadería } \\
\text { en almacén }\end{array}$ & xxx & \\
\hline \multicolumn{1}{c}{ Compras de inventarios en tránsito } & & $\mathrm{xxx}$ \\
\hline 1.01 .06 .01 .02 & \multicolumn{1}{c}{$\begin{array}{l}\text { Pr compra de inventario a proveedor xxx factura } \\
7589, \text { se cancela con transferencia 584936 Banco } \\
\text { de Loja. }\end{array}$} & & \\
\hline
\end{tabular}

\section{Conclusiones.}

- La contabilidad es de suma importancia para el desempeño empresarial, puesto que a través de procedimientos de las cuentas y presentación oportuna y confiable de los estados financieros en base a normativas contables y tributarias vigentes en el Ecuador y a nivel mundial, facilitando la toma de decisiones y el cumplimiento de obligaciones en lo referente a declaraciones mensuales y anuales, y demás disposiciones establecidas por los organismos de control encargados.

- En el aspecto empresarial es de vital importancia contar con procedimientos contables tributarios que permitan a los integrantes de la empresa contar con una herramienta clara y específica que facilite su trabajo orientado a la consecución eficiente de los objetivos financieros que faciliten la toma de decisiones de manera oportuna.

- En la empresa Tracto Oruga se detectó que la mayor parte de los procesos de importaciones se los realiza sin considerar todos los costos en los que se incurre hasta recibir la mercadería, lo que conlleva a que los precios ofertados a los clientes no se ajusten al costo real de los productos importados, perjudicando al resultado final.

- Con la elaboración de procedimientos contables y tributarios en las importaciones de la empresa Tracto Oruga contará con una herramienta que permitirá mejorar las compras de repuestos en el exterior y tener un mayor control desde el momento de adquisición hasta su venta final, en vista que su estructura está presentada por medio de flujogramas y matrices de procedimientos, los cuales describen las actividades y responsabilidades de cada trabajador, logrando incrementar los resultados de manera eficiente.

\section{Referencias bibliográficas.}

Álvarez, M. (1996). Manual para elaborar manuales de políticas y procedimientos. México D.F.: Panorama ediciones.

Ámez, F. (2002). Diccionario de contabilidad y finanzas (Primera Edición ed.). Madrid, España: Cultural S.A. 
Asamblea Nacional Constituyente (2017). Ley de Régimen Tributario Interno. Quito: Ediciones Legales.

Asamblea Nacional Constituyente (2019). Código Organico de la Producción, Comercio e Inversiones. Quito: Ediciones Legales.

Balseca, M. (2012). Equidad y Desarrollo. Quito, Ecuador: Sesos creación visual.

Carvalho, J. (2009). Estados Financieros normas para su preparación y presentación (Segunda edición ed.). Bogotá, Colombia: ECOE Ediciones.

Estrada, L. (2012). Como hacer importaciones (Guía Practica; gerencial y operativa para realizar compras a nivel internacional) (Tercera Edición ed.). Quito, Ecuador: Empresdane Gráficas Cía. Ltda.

Estupiñán, R. (2017). Estados Financieros Básicos bajo NIC/NIIF (Tercera edición ed.). Bogotá, Colombia: ECOE Ediciones.

Goxens, A., y Goxens, M. (2000). Enciclopedia Práctica de la contabilidad (Primera Edición ed.). Barcelona, España: Oceano Grupo Editorial, S.A.

Illescas, C. (2012). Marco conceptual y estados financieros (Primeda edición ed.). Loja, Ecuador: EDILOJA Cía. Ltda.

Moreno, J. (2013). Contabilidad Superior. México: Grupo Editorial Patria.

Omeñaca, J. (2017). Contabilidad General (Tercera edición ed.). Barcelona, España: DEUSTO.

Palomares, J., y Peset, M. (2015). Estados Financieros (Primera edición ed.). Madrid, España: Pirámide.

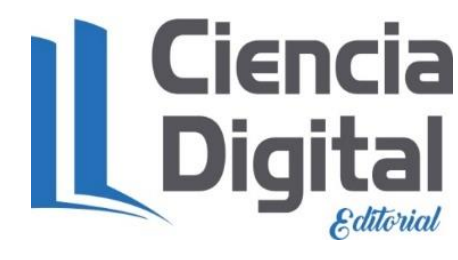




\section{PARA CITAR EL ARTÍCULO INDEXADO.}

Iñiguez Orellana, P., Narváez Zurita, C., \& Erazo Álvarez, J. (2019). Procedimientos contables y tributarios en las importaciones de la empresa Tracto Oruga y su afectación en el costeo y utilidades. Visionario Digital, 3(2.1.), 189-214. https://doi.org/10.33262/visionariodigital.v3i2.1.552

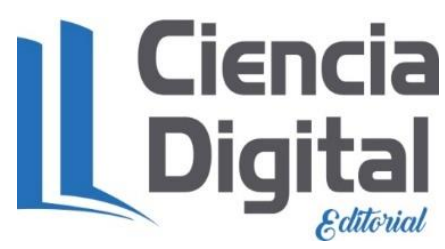

El artículo que se publica es de exclusiva responsabilidad de los autores y no necesariamente reflejan el pensamiento de la Revista Ciencia Digital.

El artículo queda en propiedad de la revista y, por tanto, su publicación parcial y/o total en otro medio tiene que ser autorizado por el director de la Revista Ciencia Digital.
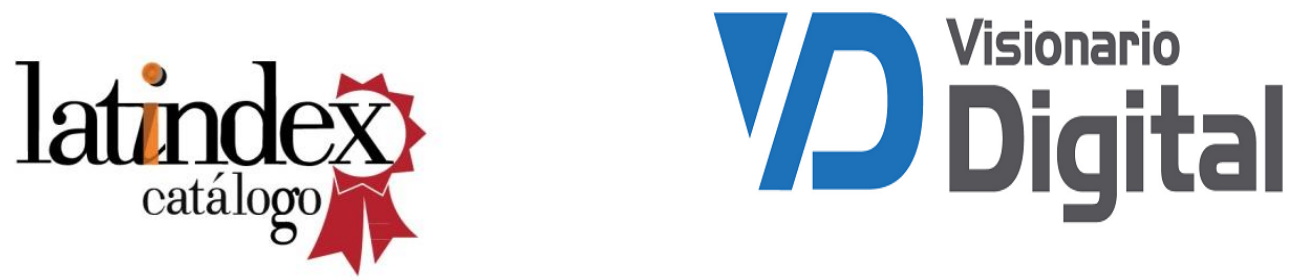